\title{
Breast lumps: rare presentation of oat cell carcinoma of lung
}

\author{
C KELLY, D HENDERSON, * P CORRIS \\ From the Departments of Thoracic Medicine and *Pathology, Freeman Hospital, Newcastle upon Tyne
}

SUMMARY Two cases of oat cell carcinoma are described. Both patients presented initially with a lump in the breast. A review of the published reports on breast metastases as a presenting feature of malignant disease was performed and lung cancer was found to be the commonest extramammary tumour to present as a breast mass ( $80 \%$ of cases) and usually as small cell carcinoma.

Secondary deposits in the breast are uncommon, accounting for only about $0.5 \%$ of all breast neoplasms. ${ }^{1}$ Occasionally, a mass in the breast may be the first indication of a tumour arising from another site. $^{2}$ We observed two cases of oat cell carcinoma of lung presenting in this manner without evidence of dissemination elsewhere, both of which responded to chemotherapy.

\section{Case reports}

\section{CASE 1}

A 64 year old woman was investigated for a painless lump in the upper outer quadrant of her left breast. She had lost $6 \mathrm{~kg}$ in weight but was otherwise well. Probable carcinoma of the breast was diagnosed clinically, and she underwent surgical removal of a well demarcated $2 \times 3 \mathrm{~cm}$ mass without further investigation. Sections of the specimen showed a very cellular malignant tumour with large areas of necrosis. Many of the cells were spindle shaped and mitotic figures were numerous. The tumour was reported as a spindle cell variant of ductal carcinoma.

A chest $x$-ray picture was then reviewed and a large left hilum was noted. Bronchoscopy was performed on the third postoperative day. This showed a tumour in the left upper lobe, which both the biopsy specimen and brushings showed to be small cell carcinoma of bronchus. The histological findings of the breast were reviewed and further sections prepared. No evidence of ductal carcinoma was detected, and in view of the close cytological similarity with the bronchial biopsy specimen it was concluded that the breast tumour was a metastasis from the bronchial carcinoma. Initially the patient responded well to oral combination chemotherapy with chloroambucil, procarbazine,

Accepted for publication 8 September 1987
VP 16 and prednisolone, and her chest $x$-ray picture became normal. She died suddenly at home seven months after diagnosis. Necropsy was not performed.

\section{CASE 2}

A 39 year old woman was referred with a $2 \times 3 \mathrm{~cm}$ mass in the lower inner quadrant of her left breast that had been present for 4 weeks. A fine needle aspiration of the mass showed a small cell carcinoma, possibly of bronchial origin, and a chest $x$-ray picture was therefore taken. This showed mediastinal enlargement, but a range of other investigations did not show any evidence of tumour at other sites. She developed superior vena caval obstruction within a week of her chest radiograph and received intravenous combination chemotherapy with the same agents as those used for case 1 in addition to radiotherapy to the mediastinum. There was considerable diminution in both her breast lump and her mediastinal mass initially, but she later developed dysphagia and deteriorated rapidly, dying six months after diagnosis.

\section{Discussion}

The forty two primary non-mammary tumours reported worldwide and presenting as a lump in the breast are shown in table $1 .^{1-6}$ Lung cancer is the commonest primary neoplasm responsible, accounting for almost half the cases. Histological examination has shown these neoplasms to be small cell carcinoma in all but four cases.

Metastasis to the breast may be a late feature in the natural history of a wide variety of tumours. A summary of all cases reported is shown in table $2 .^{1-9}$ Within this group lung cancer accounts for $15 \%$ of all recorded cases. Small cell carcinoma remains the commonest histological subgroup, although all other major histological types have been implicated.

The distribution of secondary tumours within the 
Table 1 Origin of non-mammary tumours presenting with breast lump

\begin{tabular}{lc}
\hline Tumour & $(\mathrm{N}=)$ \\
\hline Lung: & 16 \\
Small cell carcinoma & 2 \\
Adenocarcinoma & 1 \\
Squamous carcinoma & 1 \\
Carcinoid & 8 \\
Lymphoma & 3 \\
Malignant melanoma & 3 \\
Ovarian tumour & 2 \\
Carcinoid tumour of gut & 2 \\
Carcinoma of stomach & 1 \\
Carcinoma of prostate & 1 \\
Carcinoma of uterus & 1 \\
Carcinoma of kidney & 1 \\
Sarcoma & 42 \\
Total & \\
\hline
\end{tabular}

Table 2 Origin of malignant tumours metastatic to breast

Malignant melanoma

Carcinoma of lung

Carcinoma of prostate

Lymphoma

Sarcoma

Carcinoma of ovary

Carcinoma of stomach

Carcinoma of cervix

Carcinoid tumour of gut

Carcinoma of kidney

Carcinoma of colon

Carcinoma of thyroid

Carcinoma of mouth

Carcinoma of uterus

Carcinoma of parotid

Carcinoma of skin

Others

Total

56
40
39
36
18
15
13
9
8
7
6
6
6
3
2
2
6
272

breast is similar to that of the primary breast carcinoma.' About half the growths are found in the upper outer quadrant and the rest are distributed evenly throughout the breast. The histological diagnosis of mestastatic mammary malignancy can be extremely difficult. A high level of suspicion is necessary whenever the tumour has unusual appearances and is difficult to classify. Histological clues to the diagnosis include the pattern of spread, and absent in situ component, and absent elastosis. ${ }^{10}$
The initial diagnosis of a spindle cell variant of ductal carcinoma in case 1 was difficult to substantiate in the $\underline{\underline{0}}$ absence of obvious areas of ductal carcinomatosis. Small cell neoplasia may be spindle shaped, although $\stackrel{(㇒)}{\rightarrow}$ it usually occurs as small oval shaped cells (oat cells). A metastasis from an oat cell carcinoma composed of 을 spindle shaped cells may cause diagnostic problems, $\frac{\bar{T}}{\vec{D}}$ although the cytological features and pattern usually $\unrhd$ mimic the primary tumour on detailed examination. ळ

A review of the cases reported worldwide to date $\vec{A}$ shows that: (i) lung cancer is the commonest extramammary neoplasm to present as a breast mass; $\vec{\omega}$ (ii) lung cancer presenting in this way is of the small cell type in about $80 \%$ of cases; and (iii) breast?응 metastasis can be an early feature of small cell lung $\stackrel{A}{A}$ cancer and may respond to oral or intravenous $\overrightarrow{\mathrm{N}}$ chemotherapy.

\section{References}

1 Nielsen M, Anderson JA, Henrikson PW, et al. Metastases to the breast from extramammary carcinomas. Acta Pathol Microbiol 0 Scand (Section A) 1981;89:251-6.

2 Toombs BD, Kalisher L. Metastatic disease to the breast; clinical, pathological and radiographic features. $J$ Roentgenol 1977;129:673-6.

3 Sandison AT. Metastatic tumours in the breast. Br J Surg $\infty$ 1958;47:54-8.

4 Hadju SI, Urban JA. Cancers metastatic to the breast. Cancer 1972;: 1692-6.

5 McIntosh IH, Hooper AA, Millis RR, Greening WP. Metastatic carcinomas within the breast. Clin Oncol 1976;2:393-401.

6 Bohman LG, Basset LW, Gold RH, Voet R. Breast metastases from extrammammary malignancies. Radiology 1982;44: 309-12.

7 Deeley TJ. Secondary deposits in the breast. Br J Cancer 1965; 19:738-43.

8 Harrist TJ, Kalisher L. Breast metastasis; an unusual manifestation of a malignant carcinoid tumour. Cancer 1977;40:3102-6.

9 Ibach JR. Carcinoma of the ovary metastatic to breast. 1964;88:410-14.

10 Azzopardi JG. Problems in breast pathology. Philadelphia: WB Saunders, 1979.

Requests for reprints to: Dr C Kelly, c/o Chest Clinic, Newcastle General Hospital, Westgate Road, Newcastle 9 upon Tyne, England. 